\title{
ФИЛОСОФИЯ
}

(специиальность: 09.00.11)

\section{УДК 1}

\section{E.E. Фёдорова}

Донской государственный технический университет

2. Ростов-на-Дону, Россия

redaction-el@mail.ru

\section{«ЦИФРОВЫЕ АБОРИГЕНЫ» \\ В НОВОМ КОММУНИКАТИВНОМ ПРОСТРАНСТВЕ}

\section{[Elena E. Fedorova "Digital natives" in the new communication space]}

The article examines the problematic features of people born after 1980, the so-called "digital natives", presents a competence model designed to show the areas of knowledge and skills that need to be offered to young people, and which will be useful for successfully managing their future in a changing world. The prevailing theoretical approach is an anthropological cultural approach with interdisciplinary contacts.

Key words: interpersonal communication, Internet, computerization, intercultural communication, interdisciplinary contacts.

Термин «цифровые аборигены» применяется к людям, родившимся после 1980-1990 годов, когда появились социальные цифровые технологии [4]. Это молодые люди, которые имеют доступ к сетевым цифровым технологиям. Использование этих технологий также изменило то, как они мыслят и обрабатывают информацию.

Одной из главных задач, стоящих перед антропологическими культурологическими исследованиями, является осмысление культурных изменений, вызванных новыми технологическими изменениями в нашем обществе. Такие изменения требуют образовательной или, в более широком смысле, формирующей модели, которая признает новые способы обучения и общения молодежи - «поколения приложений» и социальных сетей. Особенности новых медиа скорость, доступность, простота получения, передачи и преобразования информации, возможная анонимность и множественная идентичность - не могут быть проигнорированы, особенно в силу ряда проблемных аспектов. 
Некоторые из сомнительных характеристик «цифрового туземца» таковы: проблемы идентичности; нарциссизм и самореклама; сложные локальные/ глобальные отношения; растущий индивидуализм; нежелание брать на себя ответственность и риск; искаженное восприятие времени. Прежде всего, мы не можем игнорировать великую трансформацию интернета, который из поставщика информации с web 2.0 превратился в социальное пространство, подчеркивая постоянный поиск социальных контактов и контактов, таких как «в любое время и в любом месте», «многие ко многим», «одноранговые», которые благоприятствуют встречам, дружбе и виртуальным и реальным сравнениям.

Исследование, проведенное Гарднером и Дэвисом, предлагает нам интересную точку зрения на процесс обучения современных молодых людей и его пределы [3]. Анализируя последствия общего и инвазивного использования приложений в повседневной жизни, авторы задаются вопросом: что на самом деле означает жизнь в «мире приложений» для будущего нашего вида и нашей планеты? Приложения - это процедуры, которые позволяют пользователю получить результат быстро и приятно. Однако у них есть последствия, которые могут оказаться негативными, потому что вторжение приложений в повседневную жизнь человека способствует построению мировоззрения, основанного на их кодах. Это «короткие пути», которые ускоряют взаимодействие, упрощают его и делают менее рискованным.

С личной точки зрения приложения охватывают совокупность интересов, привычек и отношений, которые характеризуют личность: это личная идентичность, открытая внешнему миру. Их общее использование влияет на аспекты личности, которые имеют тенденцию принимать форму «индивидуального Я» [3], позитивную и направленную на саморекламу, которая желательна, но отвлекает внимание от внутреннего Я, глубочайших чувств и личных проектов. Некоторые специфические черты, связанные с саморекламой в интернете, поощряются предполагаемой анонимностью интернета. Например, вы не показываете, как вы на самом деле живете, а только то, каким вы кажетесь, даже если образ не далек от реальности. Молодые люди на самом деле не считают свою онлайн-и офлайн-идентичность очень разными, так же как частная и публичная сферы на самом деле не считаются отдельными.

Еще один новый аспект связан с концепцией межкультурности: молодые люди знают о глобальном мировоззрении, но часто не имеют более глубоко- 
го понимания из-за плохого культурного фона, и, как добавляют авторы, они говорят глобально, но действуют локально. Приложения предоставляют им возможность получить доступ к опыту вне повседневной жизни, но неизвестно, насколько молодые действительно извлекают из них пользу, даже если принятие инаковости возросло. Это один из аспектов «уважительного ума», который подразумевает открытое отношение к знаниям и принятие людей и вещей, которые отличаются друг от друга в культурном отношении.

Новые коммуникационные технологии также играют определенную роль в том, чтобы дать молодым людям чувство безопасности, поскольку они избегают многих рисков реальной жизни, таких как поиск своего пути в неизвестных местах или столкновение лицом к лицу с неожиданными реакциями человека. В очередной раз важность сохранения постоянного контакта с реальностью и непосредственными отношениями выступает в качестве ориентира для переживания значимых отношений, что идет вразрез с тенденцией усиления изоляции и снижения эмпатии. Многие молодые люди разделяют эти характеристики, описанные выше, и готовятся к будущему со многими неопределенностями.

В качестве вывода из вышеизложенных соображений было бы полезно спросить себя, какие предложения мы можем сделать для подготовки молодежи к будущему. Технология влияет на коммуникацию, потому что она предлагает новые элементы в создании воображаемых предметов и миров. Они, как правило, интегрируют ниспровергают и трансформируют другие контекстуальные формы обучения [1]. Вот почему думать о будущем - значит отбирать и давать знания, которые пригодятся молодежи в ближайшие годы. С этой целью выделим некоторые культурные особенности, которые, по нашему мнению, играют важную роль в приобретении осведомленности, компетентности и способности решать проблемы будущего. Эти особенности призваны обеспечить молодежь необходимыми инструментами. Это приобретение осознания своей идентичности; обучение мышлению в межкультурной и междисциплинарной манере; приобретение способности к синтезу; преодоление восприятия времени как одного непрерывного момента.

Предложение, касающееся взаимоотношений между местной и глобальной культурой, фокусируется на том факте, что изучение культур других стран (и не только) помогает человеку думать о своей собственной культуре. 
Молодежь использует технологии для общения, но мало или совсем ничего не знает о странах, в которых живут молодые люди их возраста и которые полны стереотипов и предрассудков. Антропологи говорят, что нет сознательной идентичности без встречи с инаковостью, особенно если человек сосредоточивается на верованиях, традициях, языке, мифах, ритуалах, вкусах, которые при первом же воздействии отличаются от его собственных. Знакомство с другими, рефлексия и критическое осмысление самого себя позволяет осознать, что каждый человек является выражением культурной модели со своими собственными особенностями, которые проявляются только при встрече с инаковостью. Программы студенческого обмена, например, обеспечивают практическую ситуацию для переживания инаковости, что позволяет молодым людям осознать локальное измерение своей собственной культуры, которая является специфическим выражением знаний. На самом деле мы склонны считать наши убеждения, поведение, привычки, физические и эмоциональные проявления, которые разделяем с другими членами нашего общества, «естественными». Они действительно являются выражением той особой культуры, к которой мы принадлежим, которая отличается от других культур. Этноцентризм, рассматривающий собственную культуру как высшую, присущ всем группам людей. Это ментальное отношение лежит в основе многих непониманий, а также на уровне общения в межкультурных встречах и делает переговоры трудными, если не невозможными.

Это означает, что молодые люди должны научиться уделять приоритетное внимание межкультурному подходу, стимулируемому открытием и сравнением особенностей двух или более культур. Такой подход должен идти рука об руку с междисциплинарным подходом. Последняя понимается не просто как объединение различных областей знания, но и как Место встречи различных теорий и методов для создания новой точки зрения, нового подхода к проблемам, недостижимым с помощью отдельных дисциплин. Эти два подхода требуют выбора конкретного предмета (антропология, литература, история, география, искусство, история религий и т.д.) лучше всего на основе личных интересов. Таким образом, можно проложить ментальный путь, который направляет поиски в Интернет, чтобы найти то, что вы ищете, не теряясь и постоянно возвращаясь к исходной точке, и, следовательно, не дает человеку чувствовать себя подавленным когнитивной несогласованностью ситуа- 
ции, фрагментарностью и поверхностностью, характерной для многих людей, которые путешествуют по сети. Мы имеем в виду «дисциплинированный ум», один из пяти умов, которые Гарднер считает необходимыми для будущего, что требует глубокого знания теорий, методов и парадигм той или иной дисциплины [2]. Остальные четыре разума Гарднер определяет следующим образом: «синтезирующий, созидающий, уважительный (уже упомянутый) и этический», кратко резюмированный ниже.

Умение синтезировать, синтезирующее сознание является основополагающим в преодолении поверхностного и фрагментарного характера бессознательного личностного технологического процесса обучения, который благоприятствует незнанию; не отнимая ничего от положительных эффектов новых технологий и мира web 2.0, как, например, более широкое признание разнообразия (этнического, сексуального, культурного). Кроме того, синтез требует большей детализации и медленного запоминания, что подразумевает восприятие разницы между качеством и количеством данных. Последние являются характеристиками, например, многозадачности, когда люди одновременно работают на различных коммуникативных фронтах. Опять же технология благоприятствует количеству и скорости прохождения между различными технологическими опорами, но информация, которая поступает в игру, является поверхностной в ущерб качеству и аналитической правильности.

Одним из важных последствий полного погружения в сеть является нарушение восприятия времени, что является одним из революционных изменений в информационных технологиях. Искусство и литература, например, приспособлены к существующим отношениям между временем и современностью. Поведенческим и социальным наукам, искусству и литературе сегодня приходится решать ту же задачу, что и миру, который воспринимает время как ускоренное и видит настоящее как один непрерывный, нескончаемый момент. Тенденция состоит в том, чтобы жить в одном бесконечном моменте, в непосредственном настоящем, которое отменяет измерения прошлого и тем самым исключает будущее.

Согласно Гарднеру [2], «этические и созидающие умы» дополняют богатство интеллекта, которое он считает фундаментальным для будущего. Они фундаментальны, поскольку включают в себя измерение ценностей. Этический разум позволяет человеку размышлять о главных чертах той роли, кото- 
рую он играет в каждый конкретный момент своей жизни. Это очень важно, поскольку это означает, что они могут признать ответственность, присущую этой роли и вытекающее из этого морально правильное поведение. Созидающий разум является наиболее развитым в технологическом мире с особыми и бесконечными отсылками к художественно-литературной среде.

Любое исследование, направленное, чтобы понять общество и предвидеть его изменения в будущем, должно проводиться в культурно-антропологическом контексте. Он обеспечивает гибкую сеть взаимосвязей между различными областями знания, которые характеризуют все группы людей. Именно поэтому его нельзя игнорировать при анализе великих культурных и технологических изменений, затрагивающих всех людей во всем мире. Культурная антропология предоставляет методологию для сравнения различных культур (и не только) и анализа культурных изменений, где бы они ни происходили. Это дает возможность приблизить людей к «коренным» культурным продуктам, особенно ко всем видам художественного самовыражения. Они способствуют сопоставлению и пересечению границ локальных культур, дают возможность участвовать в глобальном творчестве, начиная с гордости за свое происхождение. Новые технологии, если их правильно использовать, могут помочь этому процессу и открыть свой разум для встречи с выражениями знания, задуманного другими человеческими существами.

\section{Л $И$ И}

1. Appadurai A. The future as cultural fact. Essays on the global condition. New York: Verso Book, 2013.

2. Gardner H. Five minds for the future. Boston: Harvard Business School Press, 2006.

3. Gardner H. \& Davis K. The APP generation. New Haven, CT: Yale University Press, 2014.

4. Prensky M. Digital natives, digital immigrants // Horizon. 2001. № 9(5). October. 